\title{
The Influence of Hardness and Chemical Composition on Enamel Demineralization and Subsequent Remineralization
}

Rana Alkattan, Frank Lippert, Qing Tang, George J. Eckert, Masatoshi Ando

\begin{abstract}
Objectives: The objectives were to investigate the hardness and chemical composition of sound, demineralized and $\mathrm{pH}$-cycled bovine enamel and determine their influence on demineralization and remineralization behavior. Methods: Ninety-four, $5 \times 5 \times 2-\mathrm{mm}$ bovine enamel specimens were demineralized using three different times [(24h $(n=33), 48 h(n=30)$, 96h $(\mathrm{n}=31)$ ]. The specimens were then $\mathrm{pH}$-cycled using either $367 \mathrm{ppm}$ F sodium fluoride or deionized water. Knoop hardness (HK) and energy-dispersive X-ray spectroscopy (measured elements: $\mathrm{Ca}, \mathrm{P}, \mathrm{F}, \mathrm{C}, \mathrm{Mg}, \mathrm{N}$ ) were performed at three stages (sound, after demineralization, after $\mathrm{pH}$-cycling) and transverse microradiography was performed after demineralization and pH-cycling. Comparisons were determined by ANOVA. Results: Results showed that HK, integrated mineral loss and lesion depth were significantly different between stages, demineralization times and treatments. The weight $\%$ of $\mathrm{F}$ at the surface was significantly affected by treatment, irrespective of demineralization time, while the Ca:P ratio of the enamel remained stable even after de- and remineralization protocols. The $\mathrm{F}$ in fluoride groups and the artificial saliva in non-fluoride groups were both able to induce enamel remineralization, indicating the protective effect of salivary pellicle against demineralization even in the absence of fluoride. Conclusions: Harder specimens and those with greater surface $\mathrm{F}$ weight $\%$ were less susceptible to demineralization and were more likely to remineralize. However, the amount of surface $\mathrm{Ca}$ and $\mathrm{P}$ did not influence de- or remineralization behavior.
\end{abstract}




\section{Clinical Significance}

This in vitro study can help clinicians better understand the caries process and the impact of the physical and chemical characteristics of enamel on its behavior during de- and remineralization. The over-the-counter fluoride toothpaste containing $1100 \mathrm{ppm}-\mathrm{F}$ was used, and was able to produce a mineralized enamel surface layer. 


\section{Acknowledgements}

This work was supported in part by Dental Master's Thesis Award Program from Delta Dental Foundation. The funders had no role in study design, data collection and analysis, decision to publish, or preparation of the manuscript.

The roles of authors were: conceived and designed the experiment: R.A., F.L., and M.A.; performed the study: R.A.; analyzed the data: G.J.E., and Q.T.; wrote the paper: R.A., and M.A.; reviewed and approved final submission: R.A., F.L., G.J.E., Q.T., and M.A. 


\section{Introduction}

Tooth enamel is composed of 96 mass $\%$ inorganic material and 4 mass $\%$ organic material and water [1]. The inorganic material is mainly composed of the mineral hydroxyapatite (HAP), a crystalline structure comprising calcium $(\mathrm{Ca})$ and phosphate $(\mathrm{P})$. Stoichiometrically, HAP does not completely correspond to the chemical formula $\mathrm{Ca}_{10}\left(\mathrm{PO}_{4}\right)_{6}(\mathrm{OH})_{2}$, as it contains many impurities including carbonate $(\mathrm{C})$, magnesium $(\mathrm{Mg})$, sodium $(\mathrm{Na})$ and chloride $(\mathrm{Cl})$. Carbonate, in particular, along with magnesium, cause major disturbances to HAP crystals [2]. The carbonate ions can substitute phosphate ions or hydroxyl groups and increase apatite solubility, while the magnesium ions can substitute calcium ions and inhibit crystal growth. On the other hand, fluoride ions can substitute hydroxyl groups and decrease apatite solubility [3]. Dental caries is a dynamic process that involves alternating demineralization and remineralization cycles. Several studies have reported that baseline physical and chemical characteristics of enamel greatly influence its behavior in such de- and subsequent remineralization challenges $[4,5,6]$.

Several attempts have been made to correlate the characteristics of enamel with its response to demineralization. Enamel specimens from primary teeth responded to demineralization by producing lesions of varying depths; deeper lesions were found to have higher amounts of carbon and nitrogen and lower amounts of calcium and phosphorus [7]. The hardness of dental enamel also had a strong correlation with its chemical content [8]. Areas with higher concentration of calcium and phosphorus were shown to have the highest nanohardness values. On the other hand, areas with higher sodium and magnesium concentrations showed the opposite trend. Lower microhardness values with concurrently lower calcium and phosphorus contents have been demonstrated by several others $[9,10,11]$. 
As for remineralization of enamel, it is well established that fluoride enhances this process $[12,13]$, and that the greater the amount of fluoride, the less the amount of demineralization, or the smaller the lesion depth [14,15]. Moreover, an increase in lesion size seems to be associated with an increase in the remineralization rate [4]. Lesions with higher $R$ values, which is calculated as the ratio of integrated mineral loss $(\Delta \mathrm{Z})$ to lesion depth $(\mathrm{L})$, tend to remineralize, whereas those with lower R values further demineralize [16]. Therefore, baseline lesion characteristics have a profound impact on subsequent remineralization behavior. There is an increasing tendency towards net remineralization and a decrease in further mineral loss with increasing integrated mineral loss at baseline $\left(\Delta \mathrm{Z}_{\text {base }}\right)[5,17]$. Lesion depth also plays a role, as deeper, more porous lesions have a higher tendency to remineralize than shallower, less porous lesions $[4,15]$. In the shallower lesions, the more soluble materials are more readily accessed by bacterial acids than in the deeper lesions.

Although enamel response to demineralization and remineralization challenges has been investigated in the aforementioned studies, it has not been investigated throughout all three stages of enamel behavior (sound, after demineralization and after $\mathrm{pH}$-cycling) nor has it related results from multiple methods, such as hardness, chemical composition and transverse microradiography. Hence, combining these techniques could better assess changes in both physical and chemical enamel characteristics.

Therefore, the aims of this study were to investigate the hardness and chemical composition of sound, demineralized and $\mathrm{pH}$-cycled enamel and their influence on demineralization and remineralization challenges. The null hypothesis is that there is no correlation between enamel hardness and mineral content and between susceptibility to deand remineralization. 


\section{Materials and Methods}

Study Design

This in vitro study was performed on bovine enamel specimens. Incipient subsurface caries lesions were formed at three distinct severities (24, 48 or $96 \mathrm{~h}$ of demineralization). After that, the specimens were subjected to an established $\mathrm{pH}$-cycling model during which they were exposed either to a diluted fluoride solution to promote remineralization, or deionized water. Knoop hardness (HK) and chemical analysis [energy-dispersive X-Ray spectroscopy (EDS)] were performed and compared among the sound, demineralized and pH-cycled specimens. Transverse microradiography (TMR) was performed to compare between demineralized and $\mathrm{pH}$-cycled specimens. A total of 94 specimens were included in the study, with six experimental groups (three demineralization times and two treatment regimens), which were randomly divided based on the sound HK of each specimen. Four portions of the specimens (Fig. 1) were designated as follows: Section A was used for HK for all three stages, Section B was the sound stage for EDS, Section C was after demineralization for both EDS and TMR, and Section D was after pH-cycling for both EDS and TMR.

\section{Specimen Preparation}

Extracted bovine incisor teeth were obtained (Tri State Beef, Cincinnati, OH, USA). The crowns were cut into $5 \times 5 \mathrm{~mm}$ blocks from the buccal surfaces only using a low speed saw (Isomet, Buehler, Lake Bluff, IL, USA). The teeth were stored in deionized water saturated with thymol during the sample preparation process. The dentin side of the blocks was first ground flat under deionized water with 500-grit silicon carbide grinding paper (Struers, Cleveland, PA, USA). The enamel side of the blocks was then ground under deionized water in a series of 1200-, 2400-, and 4000-grit paper. The enamel side was then polished using a 1- 
$\mu \mathrm{m}$ diamond polishing suspension on a polishing cloth. This procedure helped ensure the removal of approximately $200-300 \mu \mathrm{m}$ of surface enamel (depending on the natural curvature of the enamel surface of the specimen) to remove surface irregularities and create a flat enamel surface. The resulting specimens had a thickness range of $1.7-2.2 \mathrm{~mm}$. Specimens with cracks, hypomineralized (white spot) areas, or other surface flaws were excluded. Specimens were covered with acid-resistant nail varnish except the polished enamel surface. The prepared specimens were then stored in $100 \%$ relative humidity at $4{ }^{\circ} \mathrm{C}$ until further use.

\section{Demineralization}

In vitro incipient caries lesions were created using approximately $40 \mathrm{~mL}$ of demineralization solution $\left(0.1 \mathrm{~mol} / \mathrm{L}\right.$ lactic acid, $4.1 \mathrm{mmol} / \mathrm{L} \mathrm{CaCl}_{2} \cdot 2 \mathrm{H}_{2} \mathrm{O}, 8.0 \mathrm{mmol} / \mathrm{L}$ $\mathrm{KH}_{2} \mathrm{PO}_{4}$ ) per specimen at $37^{\circ} \mathrm{C}[16] .0 .2 \% w / v$ Carbopol C907 (BF Goodrich, Cleveland, $\mathrm{OH}, \mathrm{USA}$ ), a synthetic high molecular weight polymer, was added to the demineralization solution as a surface-protective agent to preserve the surface enamel and help create subsurface lesions. The $\mathrm{pH}$ of the demineralizing solution was adjusted to 5.0 using potassium hydroxide $(\mathrm{KOH})$. Two groups $(24 \mathrm{~h} / \mathrm{a}$ and $24 \mathrm{~h} / \mathrm{b})$ were demineralized for 24 hours, two groups ( $48 \mathrm{~h} / \mathrm{a}$ and $48 \mathrm{~h} / \mathrm{b}$ ) were demineralized for 48 hours, and two groups (96 $\mathrm{h} / \mathrm{a}$ and $96 \mathrm{~h} / \mathrm{b}$ ) were demineralized for 96 hours. The demineralization solution was not replaced during the entire demineralization period of each specimen. After demineralization, the specimens were rinsed under a steady stream of deionized water. The prepared specimens were then stored in $100 \%$ relative humidity at $4{ }^{\circ} \mathrm{C}$ until further use.

\section{pH-Cycling}

All specimens were $\mathrm{pH}$-cycled for 10 days using an established $\mathrm{pH}$-cycling model based on White [18], however, a daily 4-hour rather than 2-hour acid challenge in the 
demineralization solution was used. Treatments were performed with either a sodium fluoride solution (367 ppm F simulating a 1100 ppm F dentifrice after 1:2 dilution - groups $24 \mathrm{~h} / \mathrm{a}, 48$ h/a and $96 \mathrm{~h} / \mathrm{a}$ ) or deionized water (groups $24 \mathrm{~h} / \mathrm{b}, 48 \mathrm{~h} / \mathrm{b}$ and $96 \mathrm{~h} / \mathrm{b}$ ), with storage in artificial saliva $\left(2.20 \mathrm{~g} / \mathrm{L}\right.$ gastric mucin, $1.45 \mathrm{mmol} / \mathrm{L} \mathrm{CaCl}_{2} \bullet 2 \mathrm{H}_{2} \mathrm{O}, 5.42 \mathrm{mmol} / \mathrm{L} \mathrm{KH}_{2} \mathrm{PO}_{4}$, $6.50 \mathrm{mmol} / \mathrm{L} \mathrm{NaCl}, 14.94 \mathrm{mmol} / \mathrm{L} \mathrm{KCl}$ ) all other times. The $\mathrm{pH}$ of the artificial saliva was adjusted to 7.0 using $\mathrm{KOH}[19]$.

The $\mathrm{pH}$-cycling phase was conducted at room temperature and without stirring. Fresh artificial saliva and acid were used each day and fresh treatment solution was used prior to each treatment. The daily $\mathrm{pH}$-cycling regimen is shown in table 1 . Before the first treatment on day one, the specimens were placed in artificial saliva for $30 \mathrm{~min}$ to allow an artificial pellicle-like layer to form. After each treatment, the specimens were rinsed briefly under running deionized water. After the last treatment after ten days of $\mathrm{pH}$-cycling, the specimens were placed in artificial saliva for $30 \mathrm{~min}$ before being rinsed under a steady stream of deionized water. The prepared specimens were then stored in $100 \%$ relative humidity at $4{ }^{\circ} \mathrm{C}$ until further use.

Measurements/Analyses

Surface Hardness

The specimens were mounted individually on 1-inch acrylic blocks using sticky wax. The center portion, approximately $5 \times 3 \mathrm{~mm}$, of the specimens was used to measure the $\mathrm{HK}$ (Fig. 1). At the sound stage, a total of five baseline indentations were made using the Knoop diamond indenter (2100 HT; Wilson Instruments, Norwood, MA, USA) with a 50-gram load along a line parallel to the external surface of the specimen approximately $100 \mu \mathrm{m}$ apart from each other, and a dwell time of 11 seconds. The Knoop hardness number (KHN) for each 
specimen was derived by calculating the mean of the length of the long diagonal of the five indentations. Specimens were then randomly divided into six groups based on the sound enamel KHN ensuring equal distribution of the specimens with low $(<354)$, medium (354375), and high KHN (>375) between the groups.

After demineralization and $\mathrm{pH}$-cycling, a second and third set of five indentations were made to the left and right of the sound enamel indentations, respectively. The indentations were made approximately $100 \mu \mathrm{m}$ apart from each other and approximately $200 \mu \mathrm{m}$ from the sound enamel indentations. The extent of re-hardening, referred to as SMH recovery (\%SMHr), was then calculated using the formula by Gelhard et al. [20]:

$\%$ SMHr $=\frac{D-R}{D-B} \times 100$

Where $B$ is the mean indentation length $(\mu \mathrm{m})$ of the sound enamel specimen at baseline, $D$ is the mean indentation length $(\mu \mathrm{m})$ after demineralization, and $R$ is the mean indentation length $(\mu \mathrm{m})$ after $\mathrm{pH}$-cycling.

Energy-Dispersive X-Ray Spectroscopy

Three portions of the specimens (Fig. 1) were cut off at the sound stage (Section B), after demineralization (Section $\mathrm{C}$ ) and after $\mathrm{pH}$-cycling (Section $\mathrm{D})$ using a hard tissue microtome (Silverstone-Taylor Hard Tissue Microtome, Scientific Fabrications Laboratories, Lafayette, CO, USA) approximately $100 \mu \mathrm{m}$ in thickness. Any section thicker than $120 \mu \mathrm{m}$ was handpolished using 2400-grit silicon carbide paper to the required thickness.

The sections were subjected to energy-dispersive X-ray spectroscopy (EDS, JEOL 7800F; JEOL, Peabody, MA, USA). Analysis was done using the EDS detector (EDAX, 
Octane Super Detector) operating at $10 \mathrm{kV}$ accelerating voltage to measure the content of calcium $(\mathrm{Ca})$, phosphorus $(\mathrm{P})$, fluorine $(\mathrm{F})$, carbonate $(\mathrm{C})$, magnesium $(\mathrm{Mg})$ and nitrate $(\mathrm{N})$ in weight percent at the surface of the enamel. A horizontal line scan was made at the surface of each specimen section, measuring $100 \mu \mathrm{m}$ in length, and the mean weight percent of the chemical elements along that line was calculated.

Transverse Microradiography

Following EDS analysis, sections C (demineralized) and D (pH-cycled after demineralization) of the specimens were mounted with an aluminum step wedge on highresolution glass plates type I A (Microchrome Technology, San Jose, CA, USA). The sections were placed in the TMR-D system and radiographed at $45 \mathrm{kV}$ and $45 \mathrm{~mA}$ at a fixed distance for 12 seconds. The digital images were analyzed using the TMR software v.3.0.0.18 (Inspektor Research Systems, Amsterdam, The Netherlands). A window approximately $400 \times$ $400 \mu \mathrm{m}$ representing the entire lesion and not containing any cracks, debris, or other alterations was selected for analysis.

The following variables were recorded for each specimen: lesion depth (L), integrated mineral loss $(\Delta \mathrm{Z})$, and the maximum mineral content of the surface layer $\left(\mathrm{SZ}_{\max }\right)$. The $\%$ mineral profile of each enamel specimen's demineralized and remineralized lesion was compared with the mean sound enamel \% mineral profile [21]. The difference between the areas under the densitometric profile of the demineralized lesion and the mean sound enamel is represented by $\Delta Z_{\mathrm{d}}$. The difference between the areas under the densitometric profile of the remineralized lesion and the mean sound enamel is represented by $\Delta Z_{\mathrm{r}}$. These parameters were then converted to $\%$ change values after remineralization, as such, $\%$ remineralization $(\% R)$ represents the $\%$ change in $\Delta Z$ values: 
$\% R=\frac{\Delta Z_{d}-\Delta Z_{r}}{\Delta Z_{d}} \times 100$

Statistical Analysis

The mean and standard deviations of $\mathrm{KHN}, \mathrm{L}, \Delta \mathrm{Z}, \mathrm{SZ}_{\max }$, and surface weight $\%$ of $\mathrm{Ca}, \mathrm{P}$, $\mathrm{F}, \mathrm{C}, \mathrm{Mg}$ and $\mathrm{N}$ were obtained and analyzed using three-way ANOVA, with factors for stage (sound, demineralized, and pH-cycled), demineralization time (24, 48 or 96 hours) and treatment (fluoride solution or deionized water), as well as all two-way and three-way interactions among the factors. The mean and standard deviations of $\% \mathrm{SMHr}$ and $\% \mathrm{R}$ were also obtained and analyzed using two-way ANOVA with factors for demineralization time and treatment. A repeated effect for stage was added to the model. The normality of the data in ANOVA's analysis was validated. All pair-wise comparisons from ANOVA analysis were made using Fisher's Protected Least Significant Differences to control the overall significance level at 5\%. Pearson correlation coefficients were used to evaluate the associations among $\mathrm{KHN}, \mathrm{L}, \Delta \mathrm{Z}, \mathrm{SZ}_{\max }$, and surface weight $\%$ of $\mathrm{Ca}, \mathrm{P}, \mathrm{F}, \mathrm{C}, \mathrm{Mg}$ and $\mathrm{N}$ at the sound stage, after demineralization and after $\mathrm{pH}$-cycling. Data was analyzed using software SAS Version 9.4 (SAS Institute).

\section{Results}

Surface Hardness

Table 2 provides the data for $\mathrm{KHN}$ and $\% \mathrm{SMHr}$ for all groups. The $\mathrm{KHN}$ was significantly different between stages, demineralization times and treatments $(p<0.0001)$. The two-way interactions between stage and demineralization time, as well as between stage and treatment were significant $(\mathrm{p}<0.0001)$. The three-way interaction among stage, demineralization time and treatment was also significant $(\mathrm{p}=0.0001)$. The $\% \mathrm{SMHr}$ demonstrates that all groups re-hardened following $\mathrm{pH}$-cycling, but the re-hardening was 
significantly different between treatments $(p<0.0001)$, being greater in fluoride than nonfluoride groups.

Transverse Microradiography

Table 3 provides the data for $\mathrm{L}, \Delta \mathrm{Z}, \mathrm{SZ} \mathrm{max}_{\max }$ and $\% \mathrm{R}$. L was significantly different between stages $(p=0.003)$, demineralization times $(p<0.0001)$ and treatments $(p=0.007) . \Delta Z$ was also significantly different between stages, demineralization times and treatments $(\mathrm{p}<0.0001)$. L and $\Delta \mathrm{Z}$ were significantly greater after demineralization than after $\mathrm{pH}$-cycling in all groups, irrespective of the treatment received, except group $24 \mathrm{~h} / \mathrm{b}$ (demineralized for $24 \mathrm{~h}$ and received deionized water treatment), in which there was no significant difference after demineralization and after $\mathrm{pH}$-cycling. $\mathrm{SZ}_{\max }$ was significantly different between stages and treatments $(\mathrm{p}<0.0001)$, but not between demineralization times $(\mathrm{p}=0.201)$. Specimens had significantly higher surface zone mineralization after $\mathrm{pH}$-cycling than after demineralization in all groups, irrespective of the treatment received. Within treatments, specimens that received fluoride had significantly higher mineral density of the surface zone than those that did not. The positive values for $\% \mathrm{R}$ indicate that all groups remineralized following $\mathrm{pH}$-cycling, irrespective of the treatment received, except group $24 \mathrm{~h} / \mathrm{b}$, which further demineralized.

\section{Energy-Dispersive X-Ray Spectroscopy}

The surface weight $\%$ of $\mathrm{Ca}, \mathrm{P}, \mathrm{F}, \mathrm{C}, \mathrm{Mg}$ and $\mathrm{N}$ for all groups at three stages (sound, after demineralization and after $\mathrm{pH}$-cycling) is shown in Figure 2. The surface weight $\%$ of $\mathrm{Ca}, \mathrm{P}$, $\mathrm{C}, \mathrm{Mg}$ and $\mathrm{N}$ was not significantly affected by demineralization time or treatment. Figure 2 also demonstrates the $\mathrm{Ca}: \mathrm{P}$ ratio for all groups at three stages. The surface weight $\%$ of $\mathrm{F}$ was significantly affected by treatment, as specimens that received fluoride had higher surface 
fluorine weight $\%$ than specimens that did not $(\mathrm{p}<0.0001)$, irrespective of demineralization time, as shown in Figure 3.

Correlations Between Variables

A weak positive correlation was found between sound KHN and KHN after demineralization $(\mathrm{r}=0.31, \mathrm{p}=0.002)$, however, there was no correlation between sound $\mathrm{KHN}$ and $\mathrm{KHN}$ after $\mathrm{pH}$-cycling $(\mathrm{r}=0.07, \mathrm{p}=0.49)$.

After demineralization, there was a statistically significant but weak negative correlation between $\mathrm{KHN}$ and $\mathrm{L}(\mathrm{r}=-0.25, \mathrm{p}=0.017)$, between $\mathrm{KHN}$ and $\Delta \mathrm{Z}(\mathrm{r}=-0.32, \mathrm{p}=0.002)$ and between the surface weight $\%$ of $\mathrm{F}$ and $\mathrm{SZ}_{\max }(\mathrm{r}=0.24, \mathrm{p}=0.019)$. Furthermore, a weak positive correlation was found between KHN after demineralization and after $\mathrm{pH}$-cycling $(\mathrm{r}=0.35$, $\mathrm{p}<0.0001)$. A strong positive correlation was only found between $\mathrm{L}$ and $\Delta \mathrm{Z}$ after demineralization $(\mathrm{r}=0.91, \mathrm{p}<0.0001)$.

After $\mathrm{pH}$-cycling, there was a statistically significant moderate correlation between $\mathrm{KHN}$ and $\mathrm{L}(\mathrm{r}=-0.35, \mathrm{p}<0.0001)$, between KHN and $\Delta \mathrm{Z}(\mathrm{r}=-0.49, \mathrm{p}<0.0001)$, and between KHN and $\mathrm{SZ}_{\max }(\mathrm{r}=0.58, \mathrm{p}<0.0001)$. The $\mathrm{KHN}$ after $\mathrm{pH}$-cycling was found to be greater when the surface weight $\%$ of $\mathrm{F}$ was greater $(\mathrm{r}=0.32, \mathrm{p}=0.002)$, although this correlation was weak. Moreover, a moderate correlation was found between the surface weight $\%$ of $\mathrm{F}$ and $\mathrm{SZ}_{\max }$ $(\mathrm{r}=0.43, \mathrm{p}<0.0001)$. Additionally, $\mathrm{SZ}$ max showed a moderate negative correlation with both $\mathrm{L}$ $(\mathrm{r}=-0.42, \mathrm{p}<0.0001)$ and $\Delta \mathrm{Z}(\mathrm{r}=-0.55, \mathrm{p}<0.0001)$. A strong positive correlation was also found between $\mathrm{L}$ and $\Delta \mathrm{Z}$ after $\mathrm{pH}$-cycling $(\mathrm{r}=0.91, \mathrm{p}<0.0001)$.

\section{Discussion}


Our study is the first investigation throughout all three stages of enamel behavior (sound, after demineralization and after $\mathrm{pH}$-cycling) using multiple methods, such as hardness, chemical composition and contact microradiography. The null hypothesis was partially rejected; a correlation was found between the hardness and fluorine content and between the susceptibility to de- and remineralization, but no correlation was found for any of the other chemical elements examined.

Microhardness tests provide information on the physical property of surface enamel in response to de- and remineralization protocols. Microhardness testing has been proven to be a valid method to measure alterations in dental hard tissue [22,23]. In this current study, enamel hardness decreased as demineralization time increased, although there was no significant difference in KHN between 48 and 96 hours of demineralization. Conversely, KHN increased following pH-cycling in both fluoride and non-fluoride groups, with fluoride groups showing a greater increase. The extent of re-hardening, namely the \% $\mathrm{SMHr}$, showed that lesions that were demineralized longer were less able to re-harden following $\mathrm{pH}$-cycling, irrespective of treatment received. This behavior is in accordance with other studies $[11,24,25] . \%$ SMHr results also demonstrated that fluoride was able to cause significantly greater enamel re-hardening than non-fluoride groups. The role of fluoride in reducing enamel demineralization and enhancing remineralization $[9,14]$ as well as increasing the rate of enamel re-hardening in vitro $[9,26]$ have been previously established. However, even in the absence of fluoride, salivary pellicle seems to offer a protective effect against demineralization of enamel by providing some, although not much, re-hardening of the enamel surface $[27,28,29]$. 
Transverse microradiographs of the lesions produced in this study showed a tendency for greater mineral loss and lesion depth with increased demineralization time. This relationship has been shown in several studies [25,30,31]. On the other hand, following pH-cycling, all groups demonstrated a decrease in lesion depth and gain in mineralization, irrespective of treatment received. This is further confirmed by the positive values of $\%$ remineralization. However, this was not true for specimens that were demineralized for 24 hours and did not receive fluoride. This group conversely demonstrated no net remineralization and instead further demineralized. This can be explained by the behavior of smaller lesions during dissolution. Smaller lesions are thought to have greater solubility than larger ones, or those that are demineralized for longer, and thus have a greater tendency to demineralize further $[16,32]$. This is likely caused by a decrease in the solubility of the lesions with continued demineralization as a result of modification in the chemical composition. As specimens are placed in demineralization solutions, the more soluble material in the lesion (i.e. magnesium and carbon) is removed and the HAP is re-precipitated without the magnesium and carbonate, thereby reducing lesion solubility [5]. Conversely, larger lesions have a greater ability to remineralize. Possible reasons include their greater porosity allowing more diffusion of remineralizing solutions, and greater enamel area per unit volume of remineralizing solution. Alternatively, smaller lesions reach $\mathrm{SZ}_{\max }$ faster than larger lesions, thereby allowing larger lesions greater time to remineralize [15]. This is confirmed in the present study by the $\% \mathrm{R}$, which shows that larger, more demineralized lesions exhibited more remineralization after pH-cycling.

Fluoride, even in concentrations available in over-the-counter toothpastes, can enhance remineralization of lesions and form a highly mineralized surface layer in initially demineralized enamel and dentin specimens [14,32-34]. The maximum mineral density of the 
surface layer in the tested groups exhibited greater mineralization in the presence of fluoride than in its absence [35]. In the presence of fluoride, further dissolution is prevented as a result of re-precipitation of the dissolved minerals in the form of a fluoride-rich surface layer. Nonetheless, this surface layer was present even in the non-fluoride groups. Salivary pellicle has been shown to have a protective effect on the surface of enamel [29], and can prevent demineralization of the surface layer even in the absence of fluoride [36]. Likewise, microradiograms of both fluoridated and non-fluoridated enamel samples were able to show a distinct mineralized surface zone [37].

The results of the energy-dispersive x-ray spectroscopy showed that the chemical composition of the surface enamel did not change significantly for any of the chemical elements examined following demineralization. It has been previously demonstrated that when bovine enamel was demineralized for up to 8 days at a $\mathrm{pH}$ of 5 , the calcium at the surface only changed a few percent in weight compared to that of the sound specimens [38]. The microradiographic analysis performed in this study confirmed mineral loss following demineralization and mineral gain following $\mathrm{pH}$-cycling. This suggests that the minerals may have been lost and gained at a fixed ratio. This can be seen in the $\mathrm{Ca}: \mathrm{P}$ ratio at the three stages; which remained relatively stable irrespective of demineralization time or treatment. Several studies have shown that the composition of enamel does not seem to differ between sound and carious teeth [40], and that the $\mathrm{Ca}: \mathrm{P}$ ratio remains stable at various mineralization stages, which may indicate the stoichiometric dissolution and redeposition behavior of minerals in bovine enamel [9,39]. On the other hand, Sabel et al. [7] found significantly lower amounts of calcium and phosphorus parallel to greater amounts of carbon and nitrogen in lesions compared with sound enamel. However, this study was performed on primary human enamel, which is of greater porosity and has a higher tendency for dissolution $[41,42]$. 
Furthermore, the demineralization protocol used by Sabel et al. was done using methylcellulose gel for 30 days. Research regarding the appropriateness of replacing bovine for human teeth has shown that subtle morphological differences do exist between the two substrates, as both tissues behave similarly but not necessarily identically [25,43]. Bovine enamel was found to be more porous, and have higher carbonate [24] but lower fluoride contents [44]. However, the two behave similar enough to provide an acceptable alternative with the advantage of reduced variability of the hard tissue substrate [45].

In this study, the weight $\%$ of fluorine showed a significant positive correlation with the surface mineralization, which became stronger following fluoride treatment during $\mathrm{pH}$ cycling. Additionally, a negative moderate correlation was found between the mineralization of the surface layer and both the lesion depth and integrated mineral loss of the specimens. This indicates that the presence of fluoride facilitated the incorporation of minerals into the lesion thereby decreasing susceptibility to further demineralization. This effect of fluoride in reducing enamel demineralization in a dose-dependent manner was previously established [14], as the authors were able to show that mineral loss decreased as fluoride concentrations increased from 70 to $280 \mathrm{ppm} \mathrm{F}$. The existence of this relatively intact surface layer also functions to distinguish the subsurface caries lesions created in this study from the chemical etching of enamel [30].

Regarding the correlations between Knoop hardness numbers at various stages, it can be seen that specimens with greater hardness at the sound stage and following demineralization also had greater hardness after demineralization and $\mathrm{pH}$-cycling, respectively, although these correlations were weak. If hardness is considered a measurement of the presence, mineralization, or thickness of the surface layer, as well as a measurement of the subsurface 
demineralization, then these results may indicate that when a mineralized surface layer was present, the specimens maintained their structural integrity throughout de- and remineralization challenges. However, due to the weak correlation, this data should not be over-interpreted. Comparably, previous research did not find significant correlations between the indentation length of sound specimens and the change in indentation length after demineralization of the specimens for up to 48 hours, using either Knoop or Vickers indenters [25].

Following demineralization and $\mathrm{pH}$-cycling, the susceptibility of enamel to remineralization was influenced by the hardness of the specimen after demineralization, and not its hardness at the sound stage. In other words, no correlation was found between the sound hardness of enamel and its de- or remineralization potential. Therefore, susceptibility of enamel to remineralization may be more dependent on its demineralized characteristics than sound baseline values. In this study, the hardness correlated weakly to moderately with the mineral loss and lesion depth determined by transverse microradiography. Previous studies have either shown similar $[32,46]$, or conflicting $[24,25,47]$ results. One possible explanation for the difference in results could be the protocol used for demineralization. Weaker correlations for Carbopol lesions, as used in this study, were found compared to the other demineralization protocols [32]. Additionally, deeper lesions with greater subsurface mineral loss, such as those produced with Carbopol in comparison to methylcellulose (MeC) or hydroxyethylcellulose $(\mathrm{HeC})$ lesions, showed weaker relationships between hardness and TMR data $[32,46]$. Furthermore, the linearity between indentation length and lesion depth is strongly load dependent; and as such is much weaker for 50-gram loads, as used in this study, than 500-gram loads [47]. Interestingly, a significant correlation between hardness and surface zone mineralization could only be found after $\mathrm{pH}$-cycling, which stresses the role of 
fluoride in creating a highly mineralized surface layer which has re-hardened as a result of remineralization [48].

In the future, focus should be on studying the physical and chemical structure of natural white spot lesions. The similarity between human and bovine enamel does not eliminate the fact that bovine enamel is more porous and has higher carbon content that human enamel. Furthermore, lesions produced by different systems and with distinctive mineral distributions may influence the de- and remineralization characteristics.

In summary, the results from KHN showed that harder lesions after demineralization and after $\mathrm{pH}$-cycling were less susceptible to demineralization, as they showed less lesion depth and integrated mineral loss, and greater surface zone mineralization. The demineralization potential of enamel after demineralization and $\mathrm{pH}$-cycling was dependent on its hardness after demineralization and $\mathrm{pH}$-cycling, respectively, and not on the sound characteristics of enamel. Regarding fluorine, its increase correlated with the increase in both hardness and surface zone mineralization. The increase in surface zone mineralization, in turn, made lesions less susceptible to demineralization, as they showed less lesion depth and integrated mineral loss measured by transverse microradiography. Following $\mathrm{pH}$-cycling, fluoride and, to a lesser extent, non-fluoride groups were both able to remineralize. In the non-fluoride groups, shallower lesions had a greater tendency to further demineralize, while deeper lesions remineralized. The artificial saliva used in this study played a role in remineralization of the enamel in the deeper lesions, i.e. those that were demineralized longer, as evident by the increase in hardness, decrease in lesion depth, and the formation of a mineralized surface zone. 
In conclusion, harder specimens and those with greater surface $\mathrm{F}$ weight $\%$ were less susceptible to demineralization and were more likely to remineralize. However, the amount of surface $\mathrm{Ca}$ and $\mathrm{P}$ did not influence de- or remineralization behavior. 


\section{Declaration of Interest}

The authors declare that there is no conflict of interest. 


\section{Figure captions}

Figure 1. Sections of each specimen. Section A was used for HK and shows the location of the first sound enamel indentation. Section B was used for EDS analysis of the sound specimen. Section C was used for EDS and TMR analysis of the demineralized specimen. Section D was used for EDS and TMR analysis of the pH-cycled specimen.

Figure 2. Mean weight $\%$ of chemical elements at the surface in six groups at different stages (error bars omitted for better clarity).

Figure 3. Mean weight $\%$ of fluorine at the surface in six groups at different stages $(*$ indicate statistically significant differences between treatments). Error bar represents $1 \mathrm{SD}$.

Table 1. Daily $\mathrm{pH}$-cycling treatment regimen.

Table 2. Means and standard deviations for $\mathrm{KHN}$ at different stages + least square means and standard error of the least square means for $\% \mathrm{SMHr}$

Table 3. Means and standard deviations for $\mathrm{L}, \Delta \mathrm{Z}$ and $\mathrm{SZ}_{\max }$ at different stages + least square means and standard error of the least square means for $\% \mathrm{R}$ 


\section{References}

[1] A.R. ten Cate, Oral Histology: Development, Structure, and Function, fifth ed., Mosby, St Louis, 1998.

[2] E.A. Abou Neel, A. Aljabo, A. Strange, S. Ibrahim, M. Coathup, A.M. Young, L. Bozec, V. Mudera, Demineralization-remineralization dynamics in teeth and bone, Int. J. Nanomedicine 11 (2016) 4743-4763.

[3] S.E.P. Dowker, P. Anderson, J.C. Elliott, X.J. Gao, Crystal chemistry and dissolution of calcium phosphate in dental enamel, Mineralog. Mag. 63 (1999) 791-800.

[4] R. Strang, F.A. Damato, S.L. Creanor, K.W. Stephen, The effect of baseline lesion mineral loss on in situ remineralization, J. Dent. Res. 66 (1987) 1644-1646.

[5] R.J.M. Lynch, J.M. ten Cate, The effect of lesion characteristics at baseline on subsequent de- and remineralisation behavior, Caries Res. 40 (2006) 530-535.

[6] F. Lippert, The effects of lesion baseline characteristics and different Sr:Ca ratios in plaque fluid-like solutions on caries lesion de- and remineralization, Arch. Oral Biol. 57 (2012) 1299-1306.

[7] N. Sabel, A. Robertson, S. Nietzsche, J.G. Norén, Demineralization of enamel in primary second molars related to properties of the enamel, Sci. W. J. DOI: $10.1100 / 2012 / 587254$

[8] J.L. Cuy, A.B. Mann, K.J. Livi, M.F. Teaford, T.P. Weihs, Nanoindentation mapping of the mechanical properties of human molar tooth enamel, Arch. Oral. Biol. 47 (2002) 281-291.

[9] F. Feagin, T. Koulourides, W. Pigman, The characterization of enamel surface demineralization, remineralization, and associated hardness changes in human and bovine material, Arch. Oral Biol. 14 (1969) 1407-1417. 
[10] C.L. Davidson, I.S. Hoekstra, J. Arends, Microhardness of sound, decalcified and etched tooth enamel related to the calcium content, Caries Res. 8 (1974) 135-144.

[11] R.I. Ferreira, F. Haiter-Neto, C.P.M. Tabchoury, F.N. Bóscolo, In vitro induction of enamel subsurface demineralization for evaluation of diagnostic imaging methods, J. Appl. Oral Sci. 15 (2007) 392-398.

[12] J.D.B. Featherstone, T.W. Cutress, B.E. Rodgers, P.J. Dennison, Remineralization of artificial caries-like lesions in vivo by a self-administered mouthrinse or paste, Caries Res. 16 (1982) 235-242.

[13] J.R. Mellberg, W.G. Chomicki, Fluoride uptake by artificial caries lesions from fluoride dentifrices in vivo, J. Dent. Res. 62 (1983) 540-542.

[14] R.M.O. Argenta, C.P.M. Tabchoury, J.A. Cury, A modified pH-cycling model to evaluate fluoride effect on enamel demineralization, Pesqui. Odontol. Bras. 17 (2003) 241-246.

[15] J.M. ten Cate, R.A.M. Exterkate, M.J. Buijs, The relative efficacy of fluoride toothpastes assessed with pH cycling, Caries Res. 40 (2006) 136-141.

[16] F. Lippert, R.J.M. Lynch, G.J. Eckert, S.A. Kelly, A.T. Hara, D.T. Zero, In situ fluoride response of caries lesions with different mineral distributions at baseline, Caries Res. 45 (2011) 47-55.

[17] F. Schãfer, S.J. Raven, T.A. Parr, The effect of lesion characteristic on remineralization and model sensitivity, J. Dent. Res. 71 (1992) 811-813.

[18] D.J. White, Reactivity of fluoride dentifrices with artificial caries. I. Effects on early lesions: F uptake, surface hardening and remineralization, Caries Res. 21 (1987) 126140.

[19] F. Lippert, A.T. Hara, Fluoride dose-response of human and bovine enamel caries lesions under remineralizing conditions, Am. J. Dent. 25 (2012) 205-209. 
[20] T.B.F.M. Gelhard, J.M. ten Cate, J. Arends, Rehardening of artificial enamel lesions in vivo, Caries Res. 13 (1979) 80-83.

[21] G.D. Walker, F. Cai, P. Shen, D.L. Bailey, Y. Yuan, N.J. Cochrane, C. Reynolds, E.C. Reynolds, Consumption of milk with added casein phosphopeptide-amorphous calcium phosphate remineralizes enamel subsurface lesions in situ, Aust. Dent. J. 54 (2009) 245-249.

[22] J. Arends, J.J. ten Bosch, Demineralization and remineralization evaluation techniques, J. Dent. Res. 71 (1992) 924-928.

[23] D.J. White, R.V. Faller, W.D. Bowman, Demineralization and remineralization evaluation techniques - added considerations, J. Dent. Res. 71 (1992) 929-933.

[24] J.D.B. Featherstone, J.M. ten Cate, M. Shariati, J. Arends, Comparison of artificial caries-like lesions by quantitative microradiography and microhardness profiles, Caries Res. 17 (1983) 385-391.

[25] F. Lippert, R.J.M. Lynch: Comparison of Knoop and Vickers surface microhardness and transverse microradiography for the study of early caries lesion formation in human and bovine enamel, Arch. Oral Biol. 59 (2014) 704-710.

[26] D.J. White, Reactivity of fluoride dentifrices with artificial caries. II. Effects on subsurface lesions: F uptake, F distribution, surface hardening and remineralization, Caries Res. 22 (1988) 27-36.

[27] T. Koulourides, F. Feagin, W. Pigman, Remineralization of dental enamel by saliva in vitro, Ann. N Y Acad. Sci. 131 (1965) 751-757.

[28] B. Peretz, H. Sarnat, S.J. Moss, Caries protective aspects of saliva and enamel, N Y State Dent. J. 56 (1990) 25-27.

[29] J.D.B. Featherstone, J.M. Behrman, J.E. Bell, Effect of whole saliva components on enamel demineralization in vitro, Crit. Rev. Oral Biol. Med. 4 (1993) 357-362. 
[30] A. Groeneveld, J. Arends, Influence of $\mathrm{pH}$ and demineralization time on mineral content, thickness of surface layer and depth of artificial caries lesions, Caries Res. 9 (1975) 36-44.

[31] J. Arends, J. Christoffersen, M.R. Christofferesen, B. Ogaard, A.G. Dijkman, W.L. Jongebloed, Rate and mechanism of enamel demineralization in situ, Caries Res. 26 (1992) 18-21.

[32] F. Lippert, D. Churchley, R.J.M. Lynch, Effect of lesion baseline severity and mineral distribution on remineralization and progression of human and bovine dentin caries lesions, Caries Res. 49 (2015) 467-476.

[33] F. Lippert, K. Juthani, Fluoride dose-response of human and bovine enamel artificial caries lesions under pH-cycling conditions, Clin. Oral Invest. 19 (2015) 1947-1954.

[34] J.J. Damen, M.J. Buijs, J.M. ten Cate, Fluoride-dependent formation of mineralizaed layers in bovine dentin during demineralization in vitro, Caries Res. 32 (1998) 435440.

[35] R.J. Wierichs, J. Lausch, H. Meyer-Lueckel, M. Esteves-Oliveira, Re- and demineralization characteristics of enamel depending on baseline mineral loss and lesion depth in situ, Caries Res. 50 (2016) 141-150.

[36] H. Fujikawa, K. Matsuyama, A. Uchiyama, S. Nakashima, T. Ujiie, Influence of salivary macromolecules and fluoride on enamel lesion remineralization in vitro, Caries Res. 42 (2008) 37-45.

[37] J.M. ten Cate, P.P.E. Duijsters, Alternating demineralization and remineralization of artificial enamel lesions, Caries Res. 16 (1982) 201-210.

[38] C.L. Davidson, G. Boom, J. Arends, Calcium distribution in human and bovine surface enamel, Caries Res. 7 (1973) 349-359. 
[39] J.M. ten Cate, P.P.E. Duijsters, Influence of fluoride in solution on tooth demineralization. I. Chemical data, Caries Res. 17 (1983) 193-199.

[40] W.D. Armstrong, P.J. Brekhus, Chemical constitution of enamel and dentin. 1. Principal components, J. Biol. Chem. 120 (1937) 677-687.

[41] R.P. Shellis, Relationship between human enamel structure and the formation of caries-like lesions in vitro, Arch. Oral Biol. 29 (1984) 975-981.

[42] L.J. Wang, R. Tang, T. Bonstein, P. Bush, G.H. Nancollas, Enamel demineralization in primary and permanent teeth, J. Dent. Res. 85 (2006) 359-363.

[43] G.H. Yassen, J.A. Platt, A.T. Hara, Bovine teeth as substitute for human teeth in dental research: A review of literature, J. Oral Sci. 53 (2011) 273-282.

[44] J.R. Mellberg, K.L. Loertscher, Comparison of in vitro fluoride uptake by human and bovine enamel from acidulated phosphate-fluoride solutions, J. Dent. Res. 53 (1974) 64-67.

[45] J.R. Mellberg, Hard-tissue substrates for evaluation of cariogenic and anti-cariogenic activity in situ, J. Dent. Res. 71 (1992) 913-919.

[46] A.C. Magalhäes, B.M. Moron, L.P. Comar, A. Wiegand, W. Buchalla, M.A.R. Buzalaf, Comparison of cross-sectional hardness and transverse microradiography of artificial carious enamel lesions induced by different demineralizing solutions and gels, Caries Res. 43 (2009) 474-483.

[47] J. Arends, J. Schuthof, W.G. Jongebloed, Lesion depth and microhardness indentations on artificial white spot lesions, Caries Res. 14 (1980) 190-195.

[48] L.M. Silverstone, Remineralization phenomena, Caries Res. 11 (1977) 59-84. 


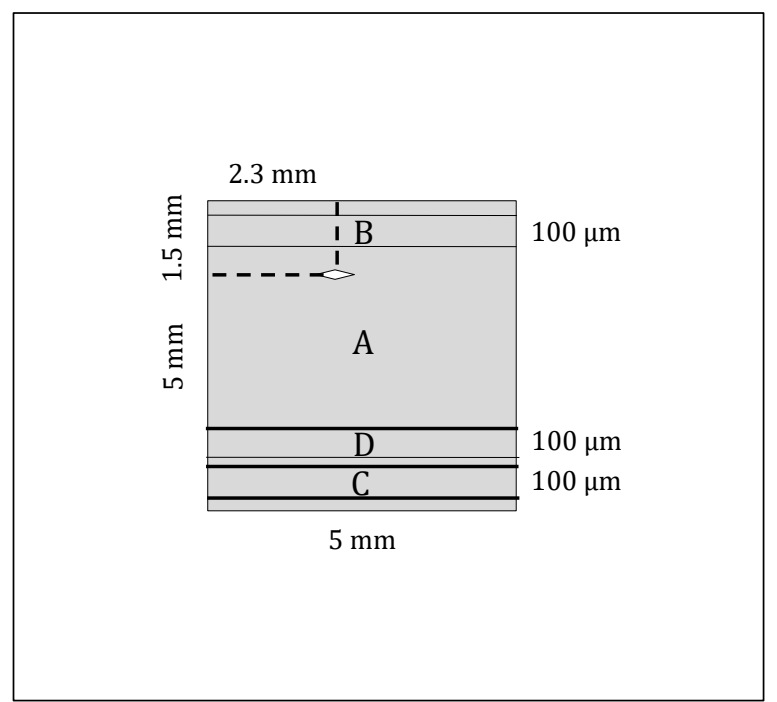

Fig. 1. Sections of each specimen. Section A was used for HK and shows the location of the first sound enamel indentation. Section B was used for EDS analysis of the sound specimen. Section C was used for EDS and TMR analysis of the demineralized specimen. Section D was used for EDS and TMR analysis of the pH-cycled specimen. 


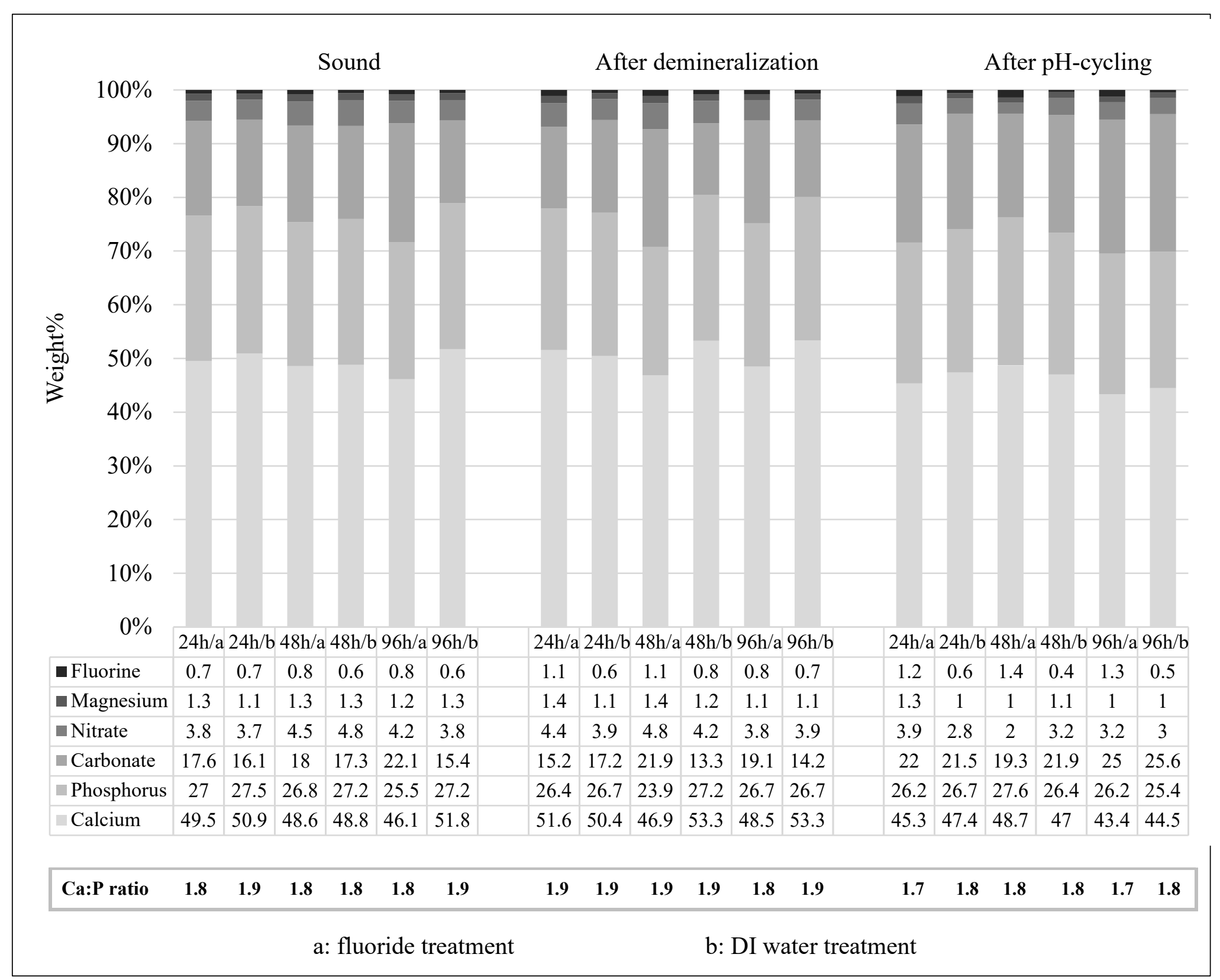

Fig. 2. Mean weight $\%$ of chemical elements at the surface in six groups at different stages (error bars omitted for better clarity). 


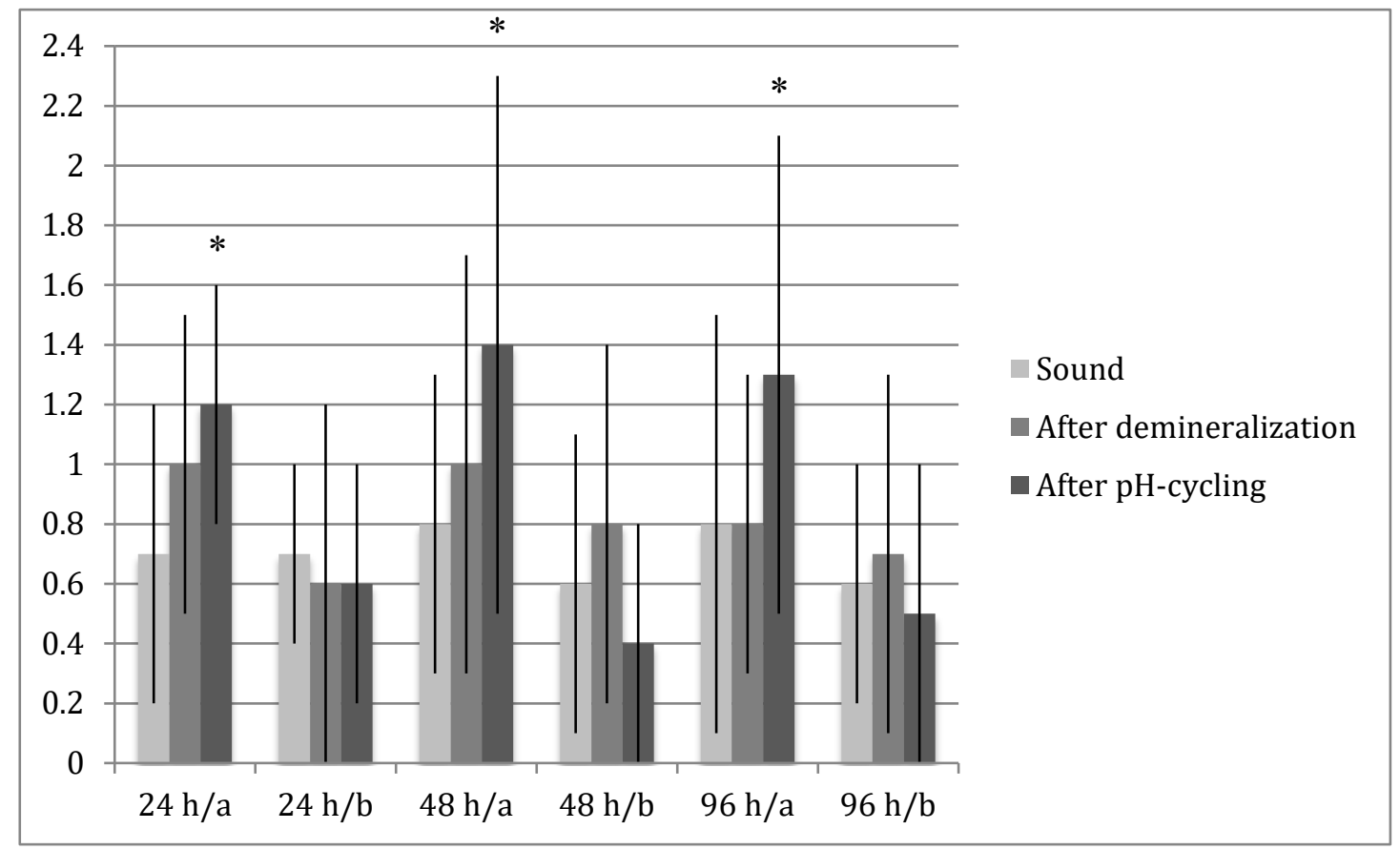

a: fluoride treatment

b: DI water treatment

Fig. 3. Mean weight $\%$ of fluorine at the surface in six groups at different stages $(*$ indicate statistically significant differences between treatments). Error bar represents 1 SD. 
Table 1. Daily $\mathrm{pH}$-cycling treatment regimen

\begin{tabular}{ll}
\hline Time frame & Specimen treatment \\
\hline 8:00-8:01 a.m. & Treatment \\
8:01-9:00 a.m. & Artificial saliva \\
9:00-9:01 a.m. & Treatment \\
9:01-10:00 a.m. & Artificial saliva \\
10:00 a.m.-2:00 p.m. & Acid challenge \\
2:00-3:00 p.m. & Artificial saliva \\
3:00-3:01 p.m. & Treatment \\
3:01-4:00 p.m. & Artificial saliva \\
4:00-4:01 p.m. & Treatment \\
4:01 p.m.-8:00 a.m. (following day) & Artificial saliva \\
\hline
\end{tabular}


Table 2. Means and standard deviations for $\mathrm{KHN}$ at different stages + least square means and standard error of the least square means for $\% \mathrm{SMHr}$

\begin{tabular}{lllllll}
\hline $\begin{array}{l}\text { Demineralization } \\
\text { time }\end{array}$ & Treatment & $\mathrm{n}$ & $\mathrm{KHN}_{\text {sound }}$ & $\mathrm{KHN}_{\text {post demin }}$ & $\mathrm{KHN}_{\text {post pH-cycling }}$ & $\% \mathrm{SMHr} \%$ \\
\hline $24 \mathrm{~h}$ & Fluoride & 15 & $364.7 \pm 15.7 \mathrm{~A}$ & $74.5 \pm 12.3 \mathrm{Ca}$ & $205.6 \pm 13.7 \mathrm{Ba} \#$ & $72.6 \pm 2.6 \#$ \\
& DI water & 18 & $365.0 \pm 24.5 \mathrm{~A}$ & $76.3 \pm 19.7 \mathrm{Ca}$ & $107.6 \pm 23.1 \mathrm{Ba}$ & $28.6 \pm 2.4$ \\
& & & & & \\
& & & & \\
& Fluoride & 15 & $357.5 \pm 23.1 \mathrm{~A}$ & $50.5 \pm 21.2 \mathrm{Cb}$ & $178.2 \pm 35.3 \mathrm{Bb} \#$ & $75.0 \pm 2.6 \#$ \\
& DI water & 15 & $361.3 \pm 26.0 \mathrm{~A}$ & $60.2 \pm 10.5 \mathrm{Cb}$ & $96.2 \pm 13.7 \mathrm{Bab}$ & $34.6 \pm 2.6$ \\
& & & & & \\
$96 \mathrm{~h}$ & Fluoride & 15 & $367.0 \pm 23.5 \mathrm{~A}$ & $61.3 \pm 12.5 \mathrm{Cb}$ & $151.3 \pm 26.6 \mathrm{Bc} \#$ & $61.1 \pm 2.6 \#$ \\
& & & & & & \\
& DI water & 16 & $370.5 \pm 23.2 \mathrm{~A}$ & $53.1 \pm 23.3 \mathrm{Cb}$ & $88.8 \pm 33.4 \mathrm{Bb}$ & $36.3 \pm 2.52$
\end{tabular}

Uppercase letters indicate statistically significant differences in KHN between stages.

Lowercase letters indicate statistically significant differences in KHN between demineralization times.

\# indicate statistically significant differences in $\mathrm{KHN}$ and \%SMHr between treatments within each demineralization time. 
Table 3. Means and standard deviations for $\mathrm{L}, \Delta \mathrm{Z}$ and $\mathrm{SZ}_{\max }$ at different stages + least square means and standard error of the least square means for $\% \mathrm{R}$

\begin{tabular}{|c|c|c|c|c|c|c|c|}
\hline $\begin{array}{l}\text { Demineralization } \\
\text { time }\end{array}$ & Treatment & $\mathrm{n}$ & Stage & $\begin{array}{l}\Delta \mathrm{Z}, \text { vol\%min } \mathrm{x} \\
\mu \mathrm{m}\end{array}$ & $\mathrm{L}, \mu \mathrm{m}$ & $\begin{array}{l}\mathrm{SZ}_{\max }, \\
\text { vol\%min }\end{array}$ & $\% \mathrm{R}, \%$ \\
\hline \multirow[t]{4}{*}{$24 \mathrm{~h}$} & Fluoride & 15 & $\begin{array}{l}\text { After } \\
\text { demineralization }\end{array}$ & $737 \pm 325 \mathrm{~A}^{*}$ & $36 \pm 20 \mathrm{~A}^{*}$ & $64 \pm 8 A^{*}$ & \multirow{2}{*}{$44.3 \pm 13.6 \#$} \\
\hline & & & After pH-cycling & $397 \pm 292 \mathrm{Ba} \#$ & $27 \pm 18 \mathrm{Ba} \#$ & $79 \pm 5 \mathrm{Ba} \#$ & \\
\hline & \multirow[t]{2}{*}{ DI water } & 18 & $\begin{array}{l}\text { After } \\
\text { demineralization }\end{array}$ & $718 \pm 341 \mathrm{~A}^{*}$ & $36 \pm 19 A^{*}$ & $62 \pm 8 \mathrm{~A}^{*}$ & \multirow{2}{*}{$-33.1 \pm 12.4$} \\
\hline & & & After pH-cycling & $809 \pm 333 \mathrm{Aa}$ & $42 \pm 26 \mathrm{Aa}$ & $67 \pm 6 \mathrm{Ba}$ & \\
\hline \multirow[t]{4}{*}{$48 \mathrm{~h}$} & \multirow[t]{2}{*}{ Fluoride } & 15 & $\begin{array}{l}\text { After } \\
\text { demineralization }\end{array}$ & $947 \pm 411 \mathrm{~A}^{*}$ & $46 \pm 21 A^{*}$ & $65 \pm 8 A^{*}$ & \multirow{2}{*}{$37.6 \pm 13.6 \#$} \\
\hline & & & After $\mathrm{pH}$-cycling & $499 \pm 378 \mathrm{Ba} \#$ & $34 \pm 22 \mathrm{Ba} \#$ & $83 \pm 6 \mathrm{Bb} \#$ & \\
\hline & \multirow[t]{2}{*}{ DI water } & 15 & $\begin{array}{l}\text { After } \\
\text { demineralization }\end{array}$ & $1114 \pm 386 \mathrm{~A}^{*}$ & $52 \pm 15 \mathrm{~A}^{*}$ & $62 \pm 10 \mathrm{~A}^{*}$ & \multirow{2}{*}{$14.9 \pm 13.6$} \\
\hline & & & After pH-cycling & $859 \pm 294 \mathrm{Ba}$ & $41 \pm 9 \mathrm{Ba}$ & $70 \pm 6 \mathrm{Bb}$ & \\
\hline \multirow[t]{4}{*}{$96 \mathrm{~h}$} & \multirow[t]{2}{*}{ Fluoride } & 15 & $\begin{array}{l}\text { After } \\
\text { demineralization }\end{array}$ & $1413 \pm 352 \mathrm{~A}$ & $65 \pm 14 \mathrm{~A}$ & $66 \pm 6 A^{*}$ & \multirow{2}{*}{$40.4 \pm 13.6 \#$} \\
\hline & & & After pH-cycling & $839 \pm 688 \mathrm{Bb} \#$ & $49 \pm 36 \mathrm{Bb} \#$ & $81 \pm 6 \mathrm{Bb} \#$ & \\
\hline & \multirow[t]{2}{*}{ DI water } & 16 & $\begin{array}{l}\text { After } \\
\text { demineralization }\end{array}$ & $1724 \pm 493 \mathrm{~A}$ & $79 \pm 26 \mathrm{~A}$ & $62 \pm 7 A^{*}$ & \multirow{2}{*}{$20.7 \pm 13.2$} \\
\hline & & & After $\mathrm{pH}$-cycling & $1363 \pm 653 \mathrm{Bb}$ & $68 \pm 28 \mathrm{Bb}$ & $71 \pm 6 \mathrm{Bb}$ & \\
\hline
\end{tabular}

Uppercase letters indicate statistically significant differences in $\mathrm{L}, \Delta \mathrm{Z}$ and $\mathrm{SZ}_{\max }$ between stages.

* indicate statistically significant differences in $\mathrm{L}, \Delta \mathrm{Z}$ and $\mathrm{SZ}_{\max }$ between demineralization times after demineralization.

Lowercase letters indicate statistically significant differences in $\mathrm{L}, \Delta \mathrm{Z}$ and $\mathrm{SZ}_{\max }$ between demineralization times after $\mathrm{pH}$ cycling.

\# indicate statistically significant differences in $\mathrm{L}, \Delta \mathrm{Z}, \mathrm{SZ}_{\max }$ and $\% \mathrm{R}$ between treatments within each demineralization time. 